\section{RMD Open}

Rheumatic \&

Musculoskeletal Diseases

To cite: Vinholt PJ, Just SA. Escaping the catch 22 of lupus anticoagulant testing. RMD Open 2020;6:e001156. doi:10.1136/ rmdopen-2019-001156

Received 6 December 2019 Revised 23 January 2020 Accepted 13 February 2020
Check for updates

(c) Author(s) (or their employer(s)) 2020. Re-use permitted under CC BY-NC. No commercial re-use. See rights and permissions. Published by BMJ.

${ }^{1}$ Clinical Biochemistry and Pharmacology, Odense University Hospital, Odense, Denmark

${ }^{2}$ Section of Rheumatology, Department of Medicine, Svendborg Hospital - Odense University Hospital, Svendborg, Denmark

Correspondence to Dr Pernille Just Vinholt; pernille.vinholt@rsyd.dk

\title{
Escaping the catch 22 of lupus anticoagulant testing
}

\author{
Pernille Just Vinholt (D) , ${ }^{1}$ Søren Andreas Just (i) ${ }^{2}$
}

\section{ABSTRACT}

High-risk patients with antiphospholipid syndrome (APS) experience increased risk of thrombosis when treated with direct oral anticoagulant (DOAC) therapy compared with warfarin. It is essential to establish the APS diagnosis to choose therapy and determine treatment duration. It requires testing for antiphospholipid antibodies, including lupus anticoagulant (LAC). In this viewpoint, we discuss the options for timing of LAC testing, which includes testing before starting anticoagulant treatment (DOAC or warfarin), after switching to heparin or after withdrawal of anticoagulant treatment. DOACs interfere with LAC testing and recommendations emerge stating not to conduct ontherapy LAC testing. All approaches are to some extent currently practised, but have limitations and the area is therefore seemingly a catch 22 . We put forward that the anticoagulant effect of DOAC can be eliminated in the laboratory and therefore patients can be tested on-therapy. While it may not eliminate all cases of interference, it could aid the interpretation in these situations and this approach is attractive from the patient and clinician's perspective. Nevertheless, to prevent misdiagnosis the diagnostic workup for APS requires collaboration between the clinician and the laboratory. We advocate for standardisation in laboratory and clinical practice when diagnosing APS.

\section{DIAGNOSE OF ANTIPHOSPHOLIPID SYNDROME}

Antiphospholipid syndrome (APS) is a clinical condition in patients with episodes of arterial thrombosis, venous thrombosis or pregnancy complications and presence of one or more of three types of antiphospholipid antibodies (aPL): lupus anticoagulant (LAC), anti- $\beta 2$-glycoprotein 1 ( $\beta 2-G P 1)$ or anticardiolipin antibodies (aCL) demonstrated 12 weeks apart. ${ }^{12}$ LAC is an in vitro phenomenon observed when antibodies interfere with phospholipid-dependent laboratory analyses resulting in elongation of clotting times. ${ }^{1}$ To rule out LAC, negative results with two methods are required. ${ }^{1}$ Most laboratories use dilute Russel's Viper Venom Time (dRVVT) as first-line test and activated partial thromboplastin time (APTT) based analysis as second-line test. ${ }^{2}$ High titres of aPL and triple positivity for LAC, aCL and anti- $\beta 2$ GPI are associated with high thrombotic risk. ${ }^{3}$

\section{THROMBOTIC RISK AND TREATMENT IN PATIENTS WITH APS}

The vitamin $\mathrm{K}$ antagonist, warfarin, has been the preferred treatment of thrombosis in patients with APS. However, the use of direct oral anticoagulant (DOAC) has been highly profiled and surpassed the use of warfarin for venous thromboembolism treatment. ${ }^{4}$ DOACs comprise dabigatran, a thrombin inhibitor; apixaban, edoxaban, rivaroxaban, which are factor Xa inhibitors. As DOACs do not need monitoring and are associated with lower risk of fatal bleeding than warfarin, their use is appealing. However, Pengo et al recently showed that DOAC treatment is associated with higher risk of arterial thrombosis than warfarin in patients with previous thrombosis and triple aPL positivity (LAC, aCL and $\beta 2-G P 1) .{ }^{5}$ The study was stopped early do to this observed imbalance. ${ }^{5}$ It is still uncertain whether DOACs are safe for some patients with APS, for example, for those who test positive for one or two aPLs or have aPL in low titre. ${ }^{67}$ Nevertheless, novel guidelines recommend that DOACs are not used in patients with APS and triple aPL positivity. ${ }^{8}$

\section{HOW TO TIME TESTING FOR ANTIPHOSPHOLIPID ANTIBODIES?}

Patients with thromboembolism can be candidates for aPL testing. ${ }^{9}$ Theoretically, sampling could be conducted before commencing treatment. While it is to some extent practised to request thrombophilia testing shortly after the thrombotic event, ${ }^{2}$ there is a risk of false positive results due to ongoing coagulation activation and interference from drugs. ${ }^{1} 1011$ Even when LAC is evaluated before commencing anticoagulation, the LAC test shall be repeated after 12 weeks time to establish a clinical diagnosis of APS. ${ }^{1}$ Instead testing can be timed to a period after withdrawal of anticoagulant treatment. However, interruption of anticoagulation will expose the patients to increased thrombotic risk. These limitations also apply for warfarin 
treatment. It is possible to switch to heparin ahead of dRVVT analysis, but the praxis is laborious, difficult to administer and thus not appropriate as a general recommendation. ${ }^{2}$ Further, APTT-based LAC analyses cannot be performed, which makes it difficult to rule out LAC if dRVVT is negative. The last option is to test patients on anticoagulant treatment. However, it has emerged, that a high rate of false results in LAC-testing is observed with all DOACs and thrombin inhibitors, especially seen in samples with rivaroxaban. ${ }^{12-17}$ Most in vitro studies found that LAC results become false-positive. False-negative LAC results in samples with apixaban has been proposed in a study based on retrospective review of laboratory data. ${ }^{17}$ Interference was observed even for samples spiked with DOAC in concentrations corresponding to through levels and below the limit of detection of commercially available tests for DOAC concentration measurements; it applied for both dRVVT and APTT-based methods. ${ }^{13} 18 \mathrm{In}$ vivo studies support these findings. ${ }^{12} 1419$ Therefore, the opinion emerges, that testing for LA should not be done while patients receive DOAC. 2021

So, can we escape this apparent catch 22? We need the test but cannot get reliable results. One simple way to handle these obstacles would be to remove the anticoagulant and/ or the anticoagulant effect from the sample prior to analysis. The DOAC-STOP (Haematex Research, Hornsby, Australia) is an insoluble commercial adsorbent material that eliminates the anticoagulant in vitro. ${ }^{15}$ DOAC-STOP can be added to samples before testing and it does not affect dRVVT in patients who do not receive DOACs. ${ }^{21}$ When using DOAC-STOP, the results from patients in DOACs can be interpreted. ${ }^{15} 19$ 22-24 A simple charcoal product (DOAC-Remove, 5-Diagnostics, Basel, Switzerland) may offer an alternative solution to eliminate anticoagulation effects before LAC testing. ${ }^{165}$ Another strategy would be to add specific reversal agents pre-analytically. Idarucizumab is a humanised monoclonal antibody fragment, which was equally effective as DOAC-STOP for reversal of dabigatran. ${ }^{26}$ Andexanet Alfa is a modified physiologically inactive human factor Xa decoy protein that binds factor Xa inhibitors with high affinity. However, the reversal of rivaroxaban with Andexanat Alfa did not eliminate the anticoagulant effect enough to prevent interference in LAC. ${ }^{27}$ Overall, elimination of DOACs in samples seems to be an option and could be combined with testing at estimated time for through DOAC levels. Finally, the sensitivity for DOACs differ among reagents for LAC and Taipan snake venom time/ecarin time might to some extent be used for patients on warfarin or rivaroxaban. ${ }^{28}$ Thus, there is an urgent need for standardisation, as quality assessments have reported false LAC results rate of $10 \%-50 \%$ with current praxis. ${ }^{2}$

\section{CLINICIAN'S PERSPECTIVE}

Current guideline states that testing should be limited to patients who have a significant probability of having the APS. ${ }^{1}$ However, it is increasingly clear that aPL testing could be relevant for all patients with thromboembolism, because the results have an impact on treatment choice and duration. In clinical practice, the indication for testing is often the choice of the clinicians. They may not all be aware of the limitations of LAC testing. ${ }^{2}$ Thus, the information regarding ongoing DOAC treatment might be lacking when the blood sample is received in the laboratory and overlocked when the results are interpreted. Therefore, it may be necessary to always have a reversal procedure included in the setup. While false-negative LAC results have been reported, reversal is relevant at least for initially positive results. Even if interference from DOACs is not eliminated in all situations, the frequency of positive LAC results would be minimised with the suggested procedure. These few LAC positive samples could result in the shift of therapy to warfarin or bridging with heparin before repeat LAC testing. In any case, a close contact between clinicians and the laboratory needs to be established to collaborate on LAC testing. ${ }^{21}$

\section{CONCLUSION}

In conclusion, patients testing triple positive for aCL, anti-32GPI and LAC are in high risk of thrombosis and should not receive DOAC but extended anticoagulation with warfarin after experiencing thrombosis. There is a clinical need for standardisation regarding how to time and manage LAC testing during ongoing anticoagulant treatment. We propose that the anticoagulant effect is sought eliminated preanalytically, which could reduce the number of false-positive LAC results combined with procedures for retesting initially positive samples is safe for the patient and feasible for the clinician. It highlights the importance of a close collaboration between the clinicians and their laboratory preventing patients from being caught in the catch 22 of lupus anticoagulant testing.

\section{Contributors Authors contributed equally in the work.}

Funding The authors have not declared a specific grant for this research from any funding agency in the public, commercial or not-for-profit sectors.

Competing interests None declared.

Patient consent for publication Not required.

Provenance and peer review Not commissioned; externally peer reviewed. Data availability statement Not relevant.

Open access This is an open access article distributed in accordance with the Creative Commons Attribution Non Commercial (CC BY-NC 4.0) license, which permits others to distribute, remix, adapt, build upon this work non-commercially, and license their derivative works on different terms, provided the original work is properly cited, appropriate credit is given, any changes made indicated, and the use is non-commercial. See: http://creativecommons.org/licenses/by-nc/4.0/.

\section{ORCID iDs}

Pernille Just Vinholt http://orcid.org/0000-0002-2035-0169

Søren Andreas Just http://orcid.org/0000-0002-3946-5919

\section{REFERENCES}

1 Pengo V, Tripodi A, Reber G, et al. Update of the guidelines for lupus anticoagulant detection. Subcommittee on lupus Anticoagulant/ Antiphospholipid antibody of the scientific and standardisation Committee of the International Society on thrombosis and haemostasis. J Thromb Haemost 2009;7:1737-40. 
2 Cohen H, Mackie IJ, Devreese KMJ, et al. Clinical and laboratory practice for lupus anticoagulant testing: an international Society of thrombosis and haemostasis scientific and standardization Committee survey. J Thromb Haemost 2019;17:1715-32.

3 Pengo V, Ruffatti A, Legnani C, et al. Incidence of a first thromboembolic event in asymptomatic carriers of high-risk antiphospholipid antibody profile: a multicenter prospective study. Blood 2011;118:4714-8.

4 Frere C, Farge D. The best direct-acting oral anticoagulant for treatment of venous thromboembolism? Lancet Haematol 2019;6:e4-5.

5 Pengo V, Denas G, Zoppellaro G, et al. Rivaroxaban vs warfarin in high-risk patients with antiphospholipid syndrome. Blood 2018;132:1365-71.

6 Peleg H, Naparstek Y, Regola F, et al. Can we use NOACS in APS? Autoimmun Rev 2019;18:102408.

7 Cohen $\mathrm{H}$, Hunt BJ, Efthymiou M, et al. Rivaroxaban versus warfarin to treat patients with thrombotic antiphospholipid syndrome, with or without systemic lupus erythematosus (RAPS): a randomised, controlled, open-label, phase $2 / 3$, non-inferiority trial. Lancet Haematol 2016;3:e426-36.

8 Tektonidou MG, Andreoli L, Limper M, et al. EULAR recommendations for the management of antiphospholipid syndrome in adults. Ann Rheum Dis 2019;78:1296-304.

9 Miyakis S, Lockshin MD, Atsumi T, et al. International consensus statement on an update of the classification criteria for definite antiphospholipid syndrome (APS). J Thromb Haemost 2006;4:295-306.

10 Ruinemans-Koerts J, Ahmed-Ousenkova YM, Kaasjager $\mathrm{HAH}$ et al. When to screen for lupus anticoagulant? Influence of testing during acute phase and consequences for clinical practise. Lupus 2015;24:1233-5.

11 Just SA, Nybo M, Laustrup $\mathrm{H}$, et al. Single test isolated lupus anticoagulant positivity is associated with increased plasma levels of inflammatory markers and dyslipidemia. Lupus 2016;25:241-7.

12 Genzen JR, Miller JL. Presence of direct thrombin inhibitors can affect the results and interpretation of lupus anticoagulant testing. Am J Clin Pathol 2005;124:586-93.

13 Flieder T, Weiser M, Eller T, et al. Interference of DOACs in different DRVVT assays for diagnosis of lupus anticoagulants. Thromb Res 2018;165:101-6.

14 Antovic A, Norberg E-M, Berndtsson M, et al. Effects of direct oral anticoagulants on lupus anticoagulant assays in a real-life setting. Thromb Haemost 2017;117:1700-4.

15 Exner T, Michalopoulos N, Pearce J, et al. Simple method for removing DOACs from plasma samples. Thromb Res 2018;163:117-22
16 Jourdi G, Delrue M, Stepanian A, et al. Potential usefulness of activated charcoal (DOAC remove $\AA$ ) for dRVVT testing in patients receiving direct oral anticoagulants. Thromb Res 2019;184:86-91.

17 Favaloro EJ, Mohammed S, Curnow J, et al. Laboratory testing for lupus anticoagulant (LA) in patients taking direct oral anticoagulants (DOACs): potential for false positives and false negatives. Pathology 2019;51:292-300.

18 Ratzinger F, Lang M, Belik S, et al. Lupus-anticoagulant testing at NOAC trough levels. Thromb Haemost 2016;116:235-40.

19 Favresse J, Lardinois B, Sabor L, et al. Evaluation of the DOACStop $\AA$ procedure to overcome the effect of DOACs on several thrombophilia screening tests. TH Open 2018;2:e202-9.

20 Tripodi A, Ageno W, Ciaccio M, et al. Position paper on laboratory testing for patients on direct oral anticoagulants. A consensus document from the SISET, FCSA, SIBioC and SIPMeL. Blood Transfus 2018;16:462-70.

21 Wayne P. Clinical and laboratory Standards Institute (CLSI): laboratory testing for the lupus anticoagulant; Approved guideline. CLSI document H60-A. CLSI, 2014.

22 Slavik L, Jacova J, Friedecky D, et al. Evaluation of the DOAC-Stop procedure by LC-MS/MS assays for determining the residual activity of dabigatran, rivaroxaban, and apixaban. Clin Appl Thromb Hemost 2019;25:107602961987255.

23 Ząbczyk M, Kopytek M, Natorska J, et al. The effect of DOACStop on lupus anticoagulant testing in plasma samples of venous thromboembolism patients receiving direct oral anticoagulants. Clin Chem Lab Med 2019;57:1374-81.

24 Platton S, Hunt C. Influence of DOAC stop on coagulation assays in samples from patients on rivaroxaban or apixaban. Int J Lab Hematol 2019;41:227-33.

25 Cox-Morton S, MacDonald S, Thomas W. A diagnostic solution for haemostasis laboratories for patients taking direct oral anticoagulants using DOAC-Remove. Br J Haematol 2019;187:377-85.

26 Jacquemin M, Toelen J, Feyen L, et al. The adsorption of dabigatran is as efficient as addition of idarucizumab to neutralize the drug in routine coagulation assays. Int $J$ Lab Hematol 2018;40:442-7.

27 Favaloro EJ, Gilmore G, Arunachalam S, et al. Neutralising rivaroxaban induced interference in laboratory testing for lupus anticoagulant (LA): a comparative study using DOAC stop and andexanet alfa. Thromb Res 2019;180:10-19.

28 Moore GW, Peyrafitte M, Dunois C, et al. Newly developed dilute Russell's viper venom reagents for lupus anticoagulant detection with improved specificity. Lupus 2018;27:95-104. 